\title{
Response repetition in pigeons: pharmacological and behavioral specificity
}

\author{
Wouter Koek ${ }^{1}$ and James H. Woods ${ }^{1,2}$ \\ ${ }^{1}$ Department of Pharmacology and \\ 2 Department of Psychology, M6322 Medical Science Building I, University of Michigan, Ann Arbor, \\ Michigan 48109-0010, USA
}

\begin{abstract}
Using a reinforcement schedule that arranges random sequences of reinforcements over two response keys, low and high probabilities of repetition of non-reinforced responses were generated in two groups of pigeons $(n=3$ per group) by varying the probability of reinforcement for responding on the key to which reinforcement was assigned. Unlike rats, the pigeons did not show a tendency to repeat just-reinforced responses, but showed a strong position bias, that was reduced by additional feeding and extinction, but not by any of the drug treatments. Apomorphine increased response repetition, irrespective of the control probability of repetition; $d$-amphetamine increased low probabilities of repetition, but decreased high probabilities. Chlordiazepoxide and scopolamine selectively decreased high probabilities of repetition; phencyclidine and pentobarbital selectively increased low probabilities of repetition. Morphine, haloperidol, chlorpromazine, additional feeding, and extinction did not affect repetition of non-reinforced responses. Extinction increased perseveration, whereas drug effects on perseveration were not observed. Drug-induced changes of patterning of responses as exemplified herein by drug-induced alterations of repetitiveness may be relevant to the interpretation of drug effects upon performance brought about by other behavioral processes such as discrimination.
\end{abstract}

Key words: Apomorphine - Amphetamine - Chlordiazepoxide - Scopolamine - Phencyclidine - Pentobarbital Morphine - Haloperidol - Chlorpromazine - Satiation Extinction - Response repetition - Response switching Pigeons

Response repetition and response switching in a situation of equivalent response alternatives have been shown to provide sensitive and important behavioral measures of effects of $d$-amphetamine. These behavioral measures are sensitive to the effects of $d$-amphetamine in that repetition and switching were affected by doses that did not alter the overall rate of responding (e.g., Robbins and Watson 1981). Effects on response repetition and switching are important because they may underlie the rate-dependent effects of $d$ amphetamine (Robbins 1981), they may underlie the apparent improvement by $d$-amphetamine of certain discrimination performances (i.e., tracking of a visual stimulus; Even-

Offprint requests to: W. Koek den and Robbins 1985), and they may underlie the disruptive effects of $d$-amphetamine on other performances (i.e., discrete trial two-choice discrimination; Koek and Slangen 1983, 1984). Further, these effects of $d$-amphetamine on repetition and switching may have implications for the understanding of certain aspects of pathological conditions (i.e., Parkinsonism, psychosis; Robbins and Sahakian 1983).

Using a schedule devised by Morgan (1974) that arranges random sequences of reinforcements over two levers, Robbins and Watson (1981) showed that the effects of $d$ amphetamine on the probability that a particular response is repeated were dependent on the control value of this probability in rats. Low probabilities of repetition were increased by $d$-amphetamine; however, at higher control values $d$-amphetamine decreased response repetition (i.e., increased switching between different responses). Further, the baseline-dependent effects of $d$-amphetamine appear to be pharmacologically selective, as evidenced by the finding that apomorphine increases response repetition irrespective of the baseline probability of repetition (Robbins 1981) and by the finding that neither chlordiazepoxide nor alpha-flupenthixol affected response repetition, even at response rate-suppressing doses.

The first aim of the present experiment was to study whether $d$-amphetamine and apomorphine produce the same effects on response repetition in pigeons as in rats and to explore further the pharmacological selectivity of these effects. An adaptation of the reinforcement schedule devised by Morgan (1974) was used. Drug effects on three different types of repetition were studied: 1) repetition of non-reinforced responses; 2) repetition of responses during the availability of reinforcement (perseveration); and 3) repetition of reinforced responses (win-stay behavior).

To provide behavioral comparisons with the drug treatments, Evenden and Robbins (1983) studied the effects of additional feeding and of extinction on response repetition. Additional feeding decreased repetition of non-reinforced responses and did not affect perseveration or repetition of reinforced responses; extinction did not affect repetition of non-reinforced responses, increased perseveration, and decreased repetition of reinforced responses. These effects of satiation and extinction were studied in rats at a high baseline probability of repetition. It was the second aim of the present study to characterize the effects of satiation and extinction on response repetition in pigeons, using different baseline probabilities of response repetition. 


\section{Materials and methods}

Subjects. Six experimentally naive White Carneaux pigeons (Palmetto, Sumter, SC) were housed individually with water and grit freely available and were maintained at $80 \%$ of their free-feeding weight by providing mixed grain in the home cage after each experimental session.

Apparatus. Experiments were conducted in ventilated, sound-attenuated chambers measuring $36 \times 28 \times 33 \mathrm{~cm}$. Three translucent response keys, $2.4 \mathrm{~cm}$ in diameter, were located on the inside of one wall, $25 \mathrm{~cm}$ from the chamber floor. The keys were $5 \mathrm{~cm}$ from each other and could be transilluminated by red $7 \mathrm{~W}$ lights located behind the wall. Mixed grain was made available for reinforcement by means of a hopper, below the center response key and $10 \mathrm{~cm}$ above the floor of the chamber. During reinforcement a white light illuminated the hopper.

A PDP-8e computer (Digital Equipment Corporation, Maynard, MA) and cumulative response recorders (Ralph Gerbrands Co., Inc., Arlington, MA), located in an adjacent room, were used for programming, data collection and recording.

Procedure. Six pigeons were trained to respond in an operant chamber, 7 days/week. After $10 \mathrm{~min}$, during which the chamber was dark and responses had no programmed consequences, the left and the right key were illuminated red. One of the two keys was selected at random $(P=0.5)$ to provide 3 -s access to grain after a key peck. Pecking the "unselected" key had no programmed consequences. Both keys remained illuminated during food presentation. After food had been presented the computer program selected at random $(P=0.5)$ which key would provide reinforcement next. The session ended after 60 reinforcements or after $1 \mathrm{~h}$, whichever occurred first.

After 7 days of exposure to this schedule, three pigeons were assigned at random to a schedule in which the probability of reinforcement for responding on the "selected" key was reduced from 1.0 to 0.3 (group $H$ ); the schedule remained the same for the other three pigeons (group L).

After 30 sessions the performance had stabilized, both in group L and in group H. From here on, every session was preceded by an IM injection (inj. vol. $1 \mathrm{ml} / \mathrm{kg}$ ) of either saline (S) or drug (D) according to the following, weekly repeating, sequence: $\mathrm{S}-\mathrm{D}-\mathrm{S}-\mathrm{D}-\mathrm{S}-\mathrm{D}-\mathrm{S}$. Data obtained during the first saline session of each sequence were used to calculate control values. Apomorphine $(0.056-1.0 \mathrm{mg} / \mathrm{kg})$, amphetamine $(0.56-5.6 \mathrm{mg} / \mathrm{kg})$, phencyclidine (PCP; 0.18-1.8 mg/kg), morphine $(1-10 \mathrm{mg} / \mathrm{kg})$, chlordiazepoxide $(1.8-18 \mathrm{mg} / \mathrm{kg})$, scopolamine $(0.01-$ $0.056 \mathrm{mg} / \mathrm{kg})$, haloperidol $(0.32-3.2 \mathrm{mg} / \mathrm{kg})$, pentobarbital $(1.8-18 \mathrm{mg} / \mathrm{kg})$ and chlorpromazine $(5.6-56 \mathrm{mg} / \mathrm{kg})$ were tested, in that order and with doses of each drug counterbalanced across pigeons.

Thereafter, effects of prefeeding (access to a quantity of mixed grain equivalent to $10 \%$ of the free-feeding body weight, during $30 \mathrm{~min}$ immediately preceding the start of the session) and extinction (mixed grain absent from the hopper with all other conditions unchanged) on schedule performance were tested, in that order. Additional feeding was conducted until a significant reduction of the overall rate of responding was observed and further testing did not produce an additional decrement of the response rate (i.e. three consecutive sessions in group $\mathrm{L}$, and five sessions in group $\mathrm{H}$ ).

Extinction tests were conducted during ten consecutive sessions. Thereafter, training was continued for 2 weeks. Finally, for each drug, the highest dose that did not completely suppress responding and the dose that did completely suppress responding in one or more pigeons per group were retested.

Measurement and data analysis. The following behavioral measures were used: 1) probability of repetition of nonreinforced responses (calculated by dividing the number of repetitions of responses on the key unselected for food delivery by the sum of repetitions of, and switches between left and right key responses); 2) perseveration (total number of responses on both keys made during presentation of the food hopper, divided by the total time, in s, during which the hopper was presented); 3) probability of repetition of reinforced responses (calculated by dividing the number of occasions on which the just-reinforced response was repeated immediately after the end of the reinforcement period by the total number of reinforcements minus 1);4) postreinforcement key bias [calculated by dividing the absolute difference between the number of left key responses and right key responses that were made immediately after reinforcement by the total number of reinforcements minus one; this ratio can attain values between zero (no bias) and 1 (complete bias)]; 5) overall rate of responding (total number of responses on both keys divided by session duration in s). Effects of drugs on these measures were analyzed by means of one-factor repeated measures analysis of variance (Keppel 1973). For each drug, the data obtained during the 2 control days intervening between tests of different doses were averaged to give a mean control value. When the results of the analysis of variance showed that the drug effect was statistically significant, Dunnett's $t$-test was used to compare the mean at each dose with the control value. Drugs were tested up to doses that affected the overall rate of responding; data obtained at dose levels at which one or more pigeons made less than 20 responses were not included in the analyses.

Drugs. The compounds used were apomorphine hydrochloride (Sigma Chemical Co., St. Louis, MO), $d$-amphetamine sulfate (Sigma Chemical Co.), PCP (Warner-Lambert/ Parke Davis and Co., Ann Arbor, MI), pentobarbital sodium (Gaines Chemical Works, New York, NY), chlordiazepoxide hydrochloride (Hoffman-La Roche, NJ), scopolamine hydrobromide (Sigma Chemical Co.), morphine sulfate (Mallinckrodt Inc., St. Louis, MO), chlorpromazine hydrochloride (Smith, Kline and French, Philadelphia, PA) and haloperidol (Janssen Pharmaceutica, Beerse, Belgium). PCP and haloperidol were dissolved in sterile water to which a small amount of lactic acid was added. All other drugs were dissolved in sterile water. Doses of drugs are expressed in the forms described above.

\section{Results}

Control performance. The mean probability of repetition of non-reinforced responses ( \pm 1 SEM), averaged across saline control sessions, was $0.24 \pm 0.06$ in group $\mathrm{L}$ and was significantly higher in group $\mathrm{H}(0.79 \pm 0.06$; Student's $t=$ $6.36, d f=4, P<0.01)$. Thus, animals in group $\mathrm{L}$ were more 
PROBABILITY OF RESPONSE REPETITION
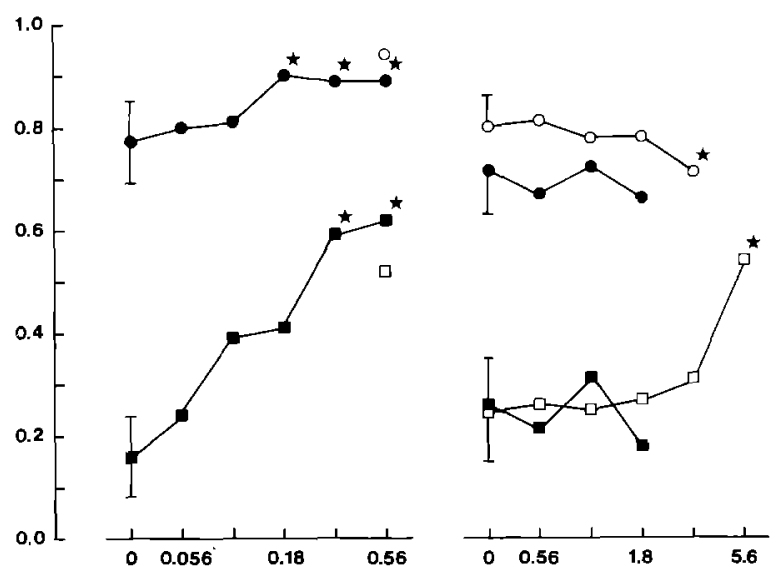

RESPONSES PER $S$
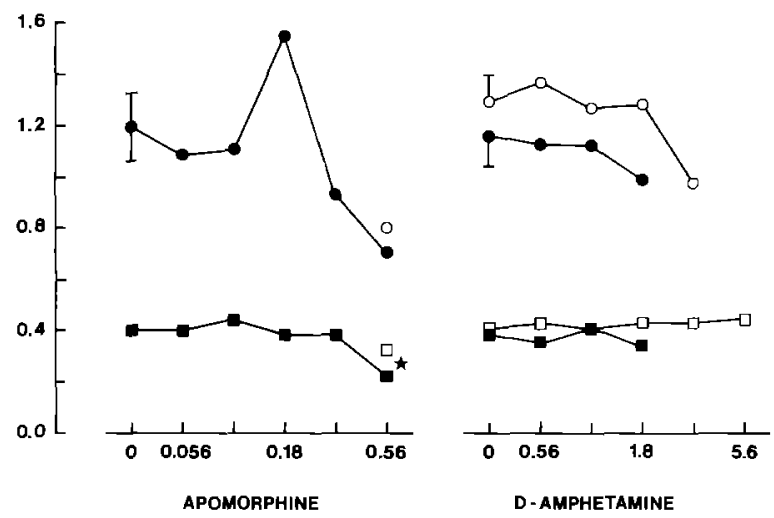

PROBABILITY OF RESPONSE REPETITION
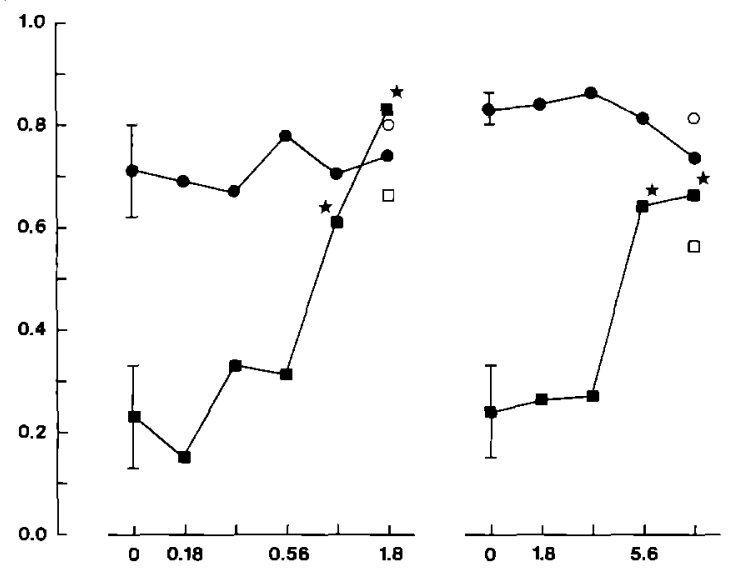

RESPONSES PER $S$

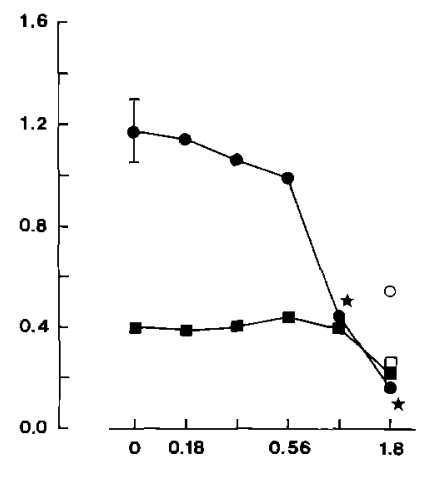

PHENCYCLIDINE
PROBAEILITY OF RESPONSE REPETITION

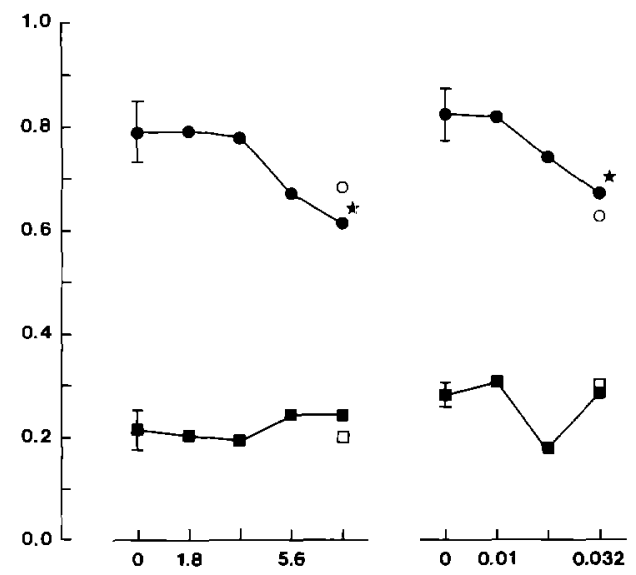

RESPONSES PER S

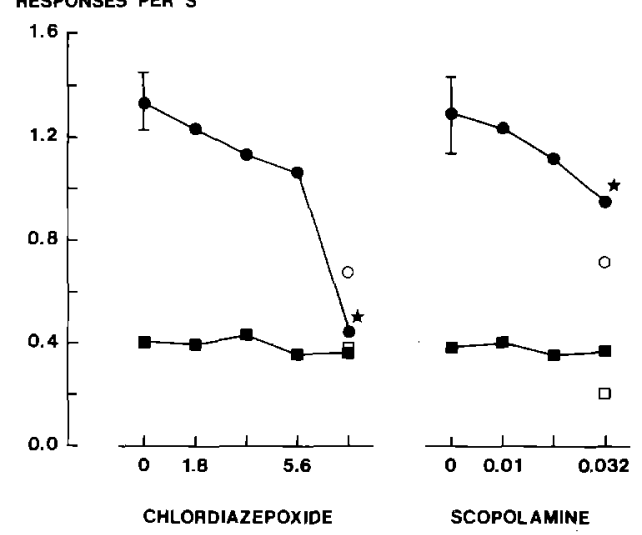




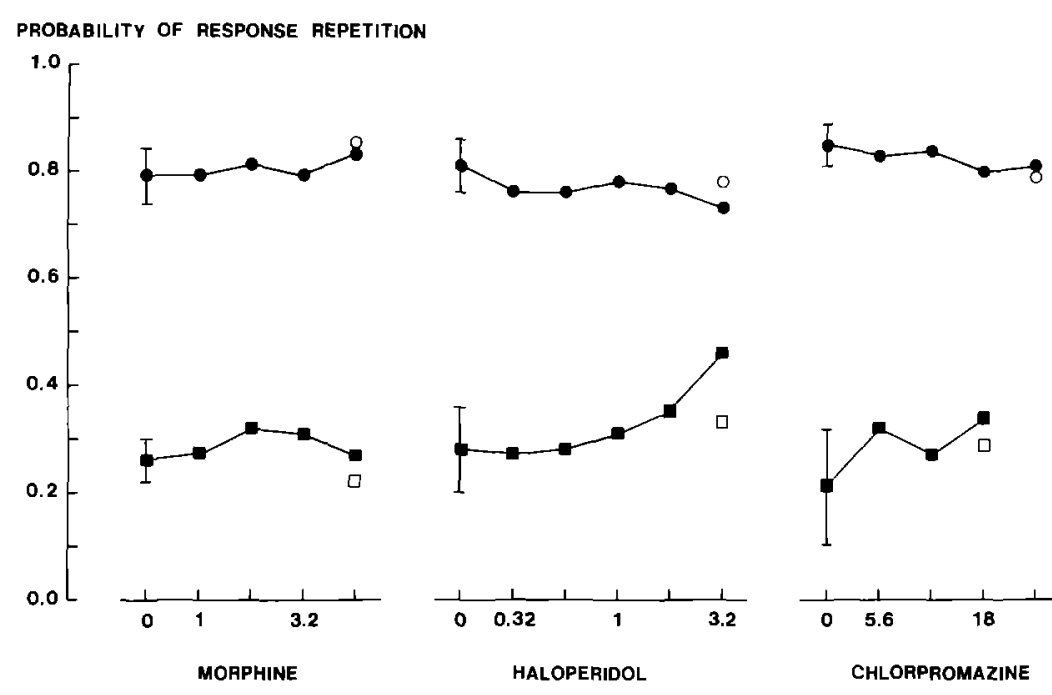

Fig. 2. Drug effects on the probability of repetition of non-reinforced responses (ordinate) in pigeons, showing a high or a low control probability of response repetition ( $n=3$ per group). Symbols as in Fig. 1. Abscissae: dose (IM) in $\mathrm{mg} / \mathrm{kg}$ likely to switch to the other key after a non-reinforced response than animals in group $\mathrm{H}$. Perseverative responding (i.e., rate of responding on the keys during the presentation of the food hopper) was not significantly different between the experimental groups $(P>0.10)$; the mean value averaged across groups was $0.05 \pm 0.03$ responses/s. The probability of repetition of reinforced responses did not differ significantly between group $\mathrm{L}$ and group $\mathrm{H}(P>0.05)$; the mean value of this probability was $0.50 \pm 0.01$ under control conditions, indicating that the pigeons did not show winstay behavior. However, the behavior shown immediately after reinforcement was not random: all pigeons showed a strong bias to respond on a particular key after the reinforcement had been presented. The overall mean value of post-reinforcement key bias was $0.83 \pm 0.05$. The overall rate of responding was significantly higher in group $\mathrm{H}$ than in group $\mathrm{L}(1.25 \pm 0.11$ and $0.39 \pm 0.01$ responses/s, respectively; Student's $t=8.21, d f=4, P<0.01$ ).

Drug effects on repetition of non-reinforced responses and response rate. Apomorphine increased the probability of repetition of non-reinforced responses (Fig. 1), both in group $\mathrm{L}[F(5,10)=4.42, P<0.05]$ and in group $\mathrm{H}[F(5,10)=$ $5.81, P<0.01]$. The response-rate reducing effects of apomorphine approached statistical significance in group $\mathrm{L}$ $[F(5,10)=3.02, P=0.06]$, but not in group $\mathrm{H}[F(5,10)=$ $1.18, P>0.2]$. Note that apomorphine increased response repetition at doses that did not significantly affect the overall rate of responding $(0.18$ and $0.32 \mathrm{mg} / \mathrm{kg})$. Note further that the results of the replication of $0.56 \mathrm{mg} / \mathrm{kg}$ apomorphine were similar to the results obtained during the first test.

During the first determination, $d$-amphetamine did not significantly affect the probability of repetition of non-reinforced responses [Fig. 1, closed symbols; group $L: F(3,6)=$ $1.23, P>0.2$; group $\mathrm{H}: F(3,6)=1.37, P>0.2]$. After the administration of $3.2 \mathrm{mg} / \mathrm{kg} d$-amphetamine, two pigeons in group $\mathrm{L}$ and one pigeon in group $\mathrm{H}$ failed to respond. However, during the second test (open symbols) all pigeons obtained the 60 available reinforcers after the administration of $3.2 \mathrm{mg} / \mathrm{kg} d$-amphetamine and all pigeons of group $\mathrm{L}$, but not of group $\mathrm{H}$, continued to respond at $5.6 \mathrm{mg} / \mathrm{kg}$ $d$-amphetamine. During the second test, $d$-amphetamine decreased the probability of repetition of non-reinforced re- sponses in group $\mathrm{H}[F(4,8)=5.73, P<0.02]$ and increased this probability in group $\mathrm{L}[F(5,10)=4.27, P<0.03]$. $d$-Amphetamine did not affect the rate of responding during the first test at the doses shown in Fig. $1[F(3,6)<1.70, P>0.2]$; during the second test, the rate-reducing effects of $d$-amphetamine approached statistical significance in group $\mathrm{H}$ $[F(4,8)=3.41, P<0.07]$, but not in group $L[F(4,8)<1.0]$.

Chlordiazepoxide and scolopamine decreased high probabilities of repetition of non-reinforced responses $[F(4,8)=5.70, P<0.02, F(3,6)=4.48, P<0.06$, respectively], without significantly affecting low probabilities $(P>$ 0.20 ). Effects on repetition were observed at doses that reduced the rate of responding in group $\mathrm{H}$ [chlordiazepoxide: $F(4,8)=10.01, P<0.01$; scopolamine: $F(3,6)=8.75, P<$ $0.02]$. In group $L$, neither drug affected the rate of responding at doses shown in Fig. $1(P>0.10)$. At least one pigeon in each experimental group did not respond after administration of $18 \mathrm{mg} / \mathrm{kg}$ chlordiazepoxide and of $0.056 \mathrm{mg} / \mathrm{kg}$ scopolamine, both during the first and the second test of this dose.

In contrast with the effects of chlordiazepoxide and of scopolamine, both PCP and pentobarbital increased response repetition in group $\mathrm{L}[F(5,10)=18.03, P<0.001$, $F(4,8)=6.99, P<0.01$, respectively] and did not affect response repetition in group $\mathrm{H}(P>0.20)$. Phencyclidine reduced the rate of responding in both groups $[F(5,10)>7.2$, $P<0.005]$. PCP $(1 \mathrm{mg} / \mathrm{kg})$ reduced the response rate in group $\mathrm{H}$, but not in group $\mathrm{L}$. Thus, in group $\mathrm{L}, 1 \mathrm{mg} / \mathrm{kg}$ PCP was found to increase response repetition without affecting the rate of responding. A dose of $1.8 \mathrm{mg} / \mathrm{kg}$ PCP reduced the response rate in both experimental groups. These effects of PCP on low probabilities of response repetition have been reported previously by Koek et al. $(1986 \mathrm{a}, \mathrm{c})$ and are included here for comparison with group $\mathrm{H}$. The effects of pentobarbital on response rate were not statistically significant $(P>0.20)$. Therefore, the effects of pentobarbital on repetition of non-reinforced responses occurred at doses that did not affect the rate of responding. At a dose of $18 \mathrm{mg} / \mathrm{kg}$, pentobarbital suppressed responding in all pigeons, during both tests.

The effects of morphine, haloperidol and chlorpromazine on repetition of non-reinforced responses (Fig. 2) were not statistically significant $(P>0.20)$. At the doses shown, significant drug effects on rate of responding were not ob- 

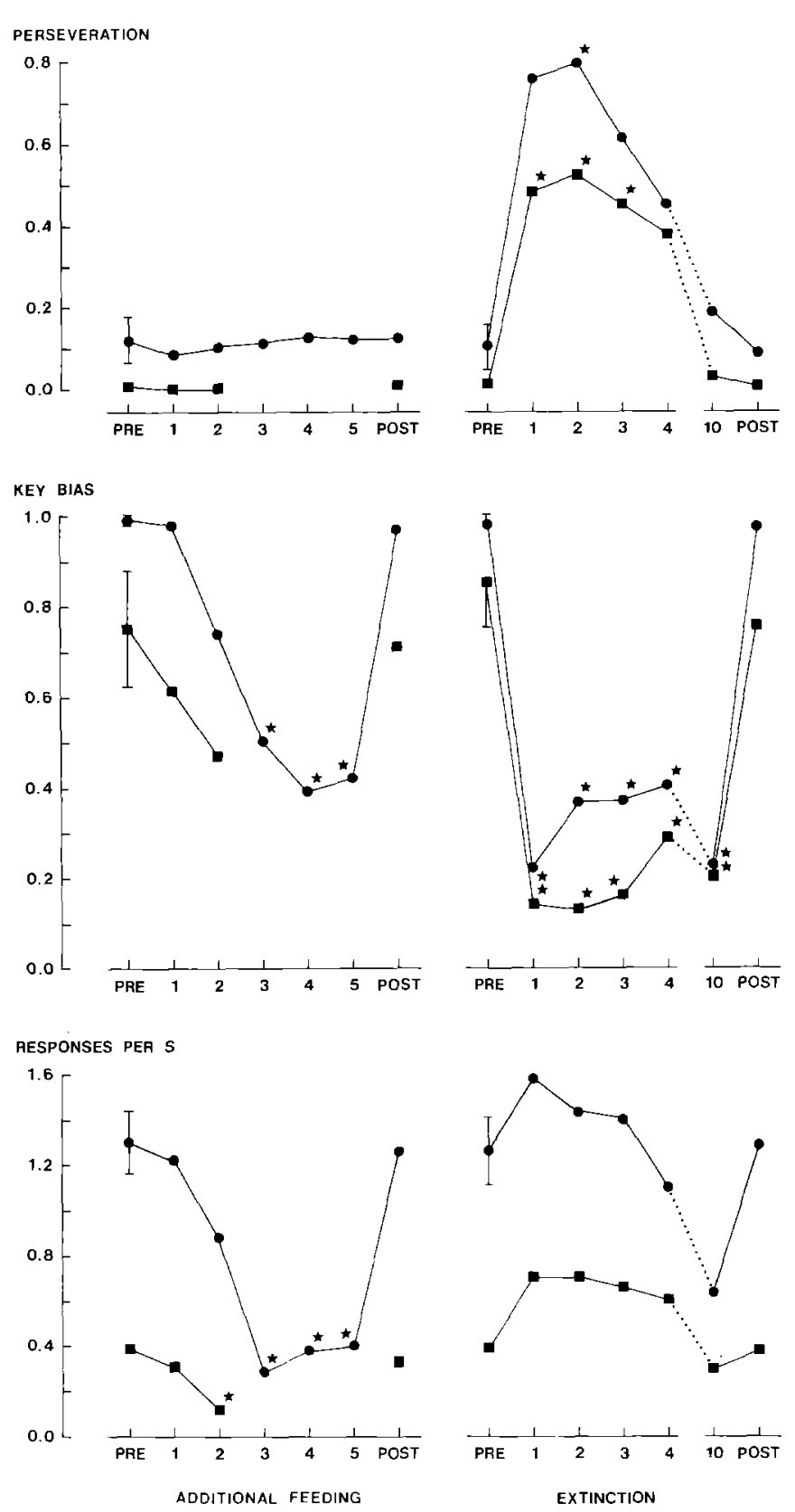

Fig. 3. Effects of additional feeding and of extinction on perseveration, key bias and response rate in pigeons that showed a high or a low control probability of response repetition $(n=3$ per group). Ordinates: perseveration (key peck responses during the presentation of the food hopper), key bias (bias to respond on a particular key immediately after the end of the hopper presentation), and response rate (measured as responses/s). Abscissae: daily sessions, before (PRE), during (numbered consecutively), and immediately after (POST) additional feeding (left panels) and extinction (right panels). Data obtained during extinction sessions 5-9 are not shown. Symbols as in Fig. 1

served $(P>0.10$; data not shown). Morphine $(10 \mathrm{mg} / \mathrm{kg})$ suppressed responding in both experimental groups, during both tests; $32 \mathrm{mg} / \mathrm{kg}$ chlorpromazine suppressed responding in group $\mathrm{L}$, and $56 \mathrm{mg} / \mathrm{kg}$ chlorpromazine suppressed responding in group $\mathrm{H}$.

Drug effects on perseveration and key bias. None of the drugs significantly affected perseveration $(P>0.10)$. Post- reinforcement key bias was attenuated by apomorphine in group $\mathrm{H}$ only [data not shown; $F(5,10)=4.21, P<0.05$ ]. A dose of $0.18 \mathrm{mg} / \mathrm{kg}$ apomorphine reduced key bias from $0.83 \pm 0.05$ to $0.64 \pm 0.10(P<0.05)$; however, the effects of higher doses of apomorphine on key bias were not statistically significant. PCP reduced post-reinforcement key bias in group $\mathrm{H}[F(5,10)=6.94, P<0.005]$, but not in group $\mathrm{L} ; 1.8 \mathrm{mg} / \mathrm{kg}$ PCP reduced bias to $0.38+0.17(P<0.05)$. Finally, morphine $(5.6 \mathrm{mg} / \mathrm{kg})$ reduced key bias to $0.6 \pm 0.1$ $(P<0.05)$, in group L only. All other drug treatments did not significantly affect post-reinforcement key bias, either in group $\mathrm{L}$ or in group $\mathrm{H}(P>0.20)$. Significant reductions of post-reinforcement key bias were not accompanied by significant changes in the probability of repeating just-reinforced responses $(P>0.20)$.

Effects of additional feeding and of extinction. Perseveration was not affected by additional feeding $(P>0.2)$, but was increased by extinction [Fig. 3; group L: $F(6,12)=4.71, P<$ 0.01 ; group $H: F(6,12)=2.41, P<0.1]$. Additional feeding decreased the bias to respond on a particular key immediately after reinforcement in group $\mathrm{H}$ [group $\mathrm{H}: F(6,12)=$ $6.84, P<0.01$; group L: $F(3,6)=2.78, P>0.10]$; extinction decreased key bias in both groups [group $L: F(6,12)=31.14$, $P<0.001$; group $\mathrm{H}: F(6,12)=15.65, P<0.001]$. Neither additional feeding nor extinction produced significant changes in the probability of repeating just-reinforced responses. Both additional feeding and extinction decreased the overall rate of responding [additional feeding: group L, $F(3,6)=$ $17.21, P<0.005$, group $\mathrm{H}, F(6,12)=15.10, P<0.001$; extinction: group L, $F(6,12)=4.07, P<0.02$, group $\mathrm{H}$, $F(6,12)=3.58, P<0.03$ ]. However, during extinction none of the response rate values for individual sessions were significantly different from their pre-extinction control values. Repetition of non-reinforced responses is not shown because this measure was not significantly affected $(P>0.20)$.

\section{Discussion}

Apomorphine increased both low and high probabilities of repetition of non-reinforced responses. Amphetamine increased low probabilities of repetition of non-reinforced responses, but decreased high probabilities, thus showing baseline-dependent effects. These drug effects in pigeons are in agreement with the effects of $d$-amphetamine and of apomorphine on repetition of non-reinforced responses in rats (Robbins 1980, 1981; Robbins and Watson 1980). However, it should be noted that in the present study effects of $d$-amphetamine on response repetition were obtained at doses that suppressed responding during the first occasion that they were tested.

Neither apomorphine nor $d$-amphetamine induced significant perseverative responding (i.e., responding on the keys during the availability of reinforcement). In rats, both apomorphine and amphetamine have been found to increase perseveration (Robbins 1980, 1981; Evenden and Robbins 1983). This difference between the findings in rats and in pigeons does not appear to result from a lack of sensitivity of the perseveration measure used in the present study, as increased perseveration was observed during extinction, in agreement with results reported in rats (Evenden and Robbins 1983).

In rats, the probability of repeating just-reinforced responses is significantly higher than the probability of 
switching to another response (Morgan 1974). This win-stay behavior is reduced by $d$-amphetamine (Robbins and Watson 1980; Evenden and Robbins 1983). In the present study no evidence was obtained for a similar win-stay tendency in pigeons. The behavior of pigeons immediately following reinforcement showed evidence of a bias to respond on a particular key, irrespective of whether a response on that key had just produced reinforcement or not. Apomorphine reduced this bias, but only at an intermediate dose; $d$-amphetamine did not affect key bias. The absence of consistent drug effects on key bias cannot be ascribed to an insensitivity of the measure used, as key bias was found to be reduced by additional feeding and during extinction.

In pigeons, effects on repetition of non-reinforced responses were not limited to apomorphine and amphetamine. PCP and pentobarbital increased low probabilities of repetition, without affecting high probabilities, in doses that did not affect the overall rate of responding. Metaphit, a proposed PCP-receptor acylator, and 2-amino-5-phosphonovalerate (AP5), an excitatory amino acid antagonist that induces PCP-like catalepsy in pigeons (Koek et al. $1986 \mathrm{~b}$ ), produced effects that were similar to the effects of PCP and pentobarbital, i.e., they increased low probabilities of response repetition, without affecting high probabilities (Koek et al. 1986a, c). Conversely, chlordiazepoxide and scopolamine decreased high probabilities of repetition without affecting low probabilities, in doses that also reduced the rate of responding. These results cannot be explained in terms of a general randomization of responding that results in a convergence of the probabilities of repetition to a value of 0.5 , because the aforementioned drugs changed one control probability of repetition, but not the other. Further, effects on repetition in pigeons do not appear to be associated invariably with any behaviorally active drug, because morphine, haloperidol and chlorpromazine were ineffective in modifying the probability of repetition of non-reinforced responses. The absence of effects of neuroleptics on repetition of non-reinforced responses is in agreement with the finding in rats that alpha-flupenthixol did not affect response repetition (Robbins and Watson 1980; Evenden and Robbins 1983). In rats, chlordiazepoxide appeared to decrease the probability of repetition, although this effect did not reach statistical significance (Evenden and Robbins 1983). As in the present study, this tendency of chlordiazepoxide to decrease high probabilities of repetition was observed only at response rate-reducing doses.

Extinction did not affect the probability of repetition of non-reinforced responses, in agreement with results obtained in rats (Evenden and Robbins 1983). Additional feeding increased switching (i.e., reduced repetition) in rats (Evenden and Robbins 1983). However, in the present study additional feeding did not affect repetition. The extinctioninduced increase of perseveration and the absence of effects of additional feeding on perseveration are consistent with the findings in rats (Evenden and Robbins 1983). None of the drugs studied herein produced effects that were similar in every respect to the effects of extinction or of additional feeding. Thus, the drug effects cannot be explained by appealing to similarities either to extinction or to satiation.

In general, the drug effects on repetition of non-reinforced responses observed in the present study are not only consistent with the effects on repetition in rats using Mor- gan's schedule, but are also consistent with effects in pigeons using a fixed-consecutive-number (FCN) schedule (Laties 1972) or a modification thereof (Evenden 1986). Laties (1972) observed that $d$-amphetamine and scopolamine, but not haloperidol, increased premature switching (i.e., decreased repetition) in a schedule that demanded that at least eight consecutive responses be made on one key, before a peck on a second key would be reinforced. In the present study, $d$-amphetamine and scopolamine, but not haloperidol, reduced high probabilities of repetition, i.e., increased low probabilities of switching, in agreement with results obtained by Laties (1972). Recently, in a detailed analysis of drug effects on performance under a modified FCN schedule, Evenden (1986) observed that $d$-amphetamine and scopolamine both increased switching, albeit in a different fashion; $d$-amphetamine increased low and high probabilities of switching, whereas scopolamine increased only low probabilities of switching. In partial agreement with these data, scopolamine decreased repetition (increased switching) when the baseline performance was characterized by a high probability of repetition (and a low probability of switching), in the present study. However, as was reported in rats using Morgan's schedule, $d$-amphetamine's effects were baseline dependent in the present study. Taken together, the data of Laties (1972), of Evenden (1986) and of the present study show that $d$-amphetamineinduced switching has considerable generality across species (rats, pigeons) and across procedures (Morgan's schedule, FCN schedule). In addition, metamphetamine was found to increase switching in monkeys (Moerschbaecher et al. 1979). However, the effects of chlorpromazine on repetition or switching appear to be more variable: increased switching (Laties 1972), decreased switching (Evenden 1986), and no effect (this study) have been obtained.

Repetition of non-reinforced responses may provide a novel behavioral measure of drug effects, in that the effects observed herein do not appear to be correlated with drug effects in other behavioral procedures. For example, all drugs used in the present study, with the possible exception of haloperidol, increase the low rates of responding engendered by fixed-interval schedules (for a review, see Robbins 1981), yet produce markedly different effects on response repetition. Thus, rate-dependent effects of drugs do not appear to be associated invariably with a particular pattern of effects on low and high probabilities of response repetition. Further, chlordiazepoxide, PCP and pentobarbital increase responding suppressed by punishment (e.g., Cook and Davidson 1973), but did not produce similar effects on response repetition. In addition, the increase of low probabilities of response repetition induced by PCP, appears to be in agreement with the impairment of spatial alternation performance caused by PCP (Glick et al. 1979). However, scopolamine, which impairs spatial alternation performance in much the same way as PCP (Glick et al. 1979), produced an effect on response repetition different from PCP. Finally, apomorphine, $d$-amphetamine, PCP and pentobarbital all increased low probabilities of response repetition, whereas directly observable stereotyped behavior in pigeons (i.e., enhanced unconditioned pecking at nonfood targets) is induced strongly by apomorphine (Cheng and Long 1974), weakly by $d$-amphetamine (Cheng et al. 1975), and does not appear to be induced by PCP or pentobarbital (unpublished observations).

The assessment of the effects of $d$-amphetamine on mea- 
sures of response repetition has contributed to the elucidation of the behavioral mechanisms that underlie the effects of $d$-amphetamine on accuracy of responding in discrimination procedures (e.g., Koek and Slangen 1983, 1984; Evenden and Robbins 1985). Further, effects of $d$-amphetamine on response repetition may also underlie its effects on repeated acquisition (Schrot and Thomas 1982; Paule and McMillan 1984). In the present study, it was found that effects on repetition of responses may be observed with drugs other than amphetamine. This finding suggests the possibility that effects of these non-amphetamine-like drugs on response repetition may also be relevant to our understanding of drug-induced changes in discrimination.

Acknowledgements. This work was supported by a Constantijn and Christiaan Huygens Career Development Award to Wouter Koek (on leave of absence from the Department of Psychophysiology, University of Utrecht, The Netherlands), received from the Netherlands Organization for the Advancement of Pure Research (Z.W.O.) and by U.S. Public Health Service Grant DA-00154.

\section{References}

Cheng HC, Long JP (1974) Dopaminergic nature of apomorphineinduced pecking in pigeons. Eur J Pharmacol 26:313-320

Cheng HC, Bhatnagar RK, Long JP (1975) Dopaminergic nature of amphetamine-induced pecking in pigeons. Eur $\mathbf{J}$ Pharmacol 33: $319-324$

Cook L, Davidson AB (1973) Effects of behaviorally active drugs in a conflict-punishment procedure in rats. In: Garattini S, Mussini E, Randall LO (eds) The benzodiazepines. Raven Press, New York, pp 327-345

Evenden JL (1986) Contrasting baseline-dependent effects of amphetamine, chlorpromazine and scopolamine on response switching in the pigeon. Psychopharmacology (in press)

Evenden JL, Robbins TW (1983) Dissociable effects of $d$-amphetamine, chlordiazepoxide and alpha-flupenthixol on choice and rate measures of reinforcement in the rat. Psychopharmacology $79: 180-186$

Evenden JL, Robbins TW (1985) The effects of $d$-amphetamine, chlordiazepoxide and alpha-flupenthixol on food-reinforced tracking of a visual stimulus by rats. Psychopharmacology $85: 361-366$

Glick SD, Cox RD, Maayani S, Meibach RC (1979) Anticholinergic behavioral effect of PCP. Eur J Pharmacol 59:103-106

Keppel G (1973) Design and analysis: a researcher's handbook. Prentice-Hall, Englewood Cliffs, NJ

Koek W, Slangen JL (1983) Effects of $d$-amphetamine and mor- phine on discrimination: signal detection analysis and assessment of response repetition in the performance deficits. Psychopharmacology 80:125-128

Koek W, Slangen JL (1984) Effects of $d$-amphetamine and morphine on delayed discrimination: signal detection analysis and assessment of response repetition in the performance deficits. Psychopharmacology 83:346-350

Koek W, Woods JH, Jacobson AE, Rice KC, Lessor RA (1986a) Metaphit, a proposed PCP receptor acylator: phencyclidinelike behavioral effects and evidence of absence of antagonist activity in pigeons and in rhesus monkeys. J Pharmacol Exp Ther 237:386-392

Koek W, Kleer E, Mudar PJ, Woods JH (1986b) Phencyclidinelike catalepsy induced by the excitatory amino acid antagonist DL-2-amino-5-phosphonovalerate. Behav Brain Res 19:257259

Koek W, Woods JH, Ornstein P (1986c) Phencyclidine-like behavioral effects in pigeons induced by systemic administration of the excitatory amino acid antagonist, 2-amino-5-phosphond valerate. Life Sci 39:973-978

Laties VG (1972) The modification of drug effects on behavior by external discriminative stimuli. J Pharmacol Exp Ther $183: 1-13$

Moerschbaecher JM, Thompson DM, Thomas JR (1979) Effects of metamphetamine and scopolamine on variability of response location. J Exp Anal Behav 32:255-263

Morgan MJ (1974) Effects of random reinforcement sequences. J Exp Anal Behav 22:301-310

Paule MG, McMillan DE (1984) Incremental repeated acquisition in the rat: acute effects of drugs. Pharmacol Biochem Behav $21: 431-439$

Robbins TW (1980) Stereotypy of a learned response after apomorphine. Brit J Pharmacol 69:275 P-276 P

Robbins TW (1981) Behavioural determinants of drug action: ratedependency revisited. In: Cooper SJ (ed) Theory in psychopharmacology, vol. 1. Academic Press, New York, pp 1-63

Robbins TW, Watson BA (1981) Effects of $d$-amphetamine on response repetition and "win-stay" behaviour in rat. In: Bradshaw CM, Szabadi E, Lowe CF (eds) Quantification of steadystate operant behaviour. Elsevier, Amsterdam, pp 441-444

Robbins TW, Sahakian BJ (1983) Behavioral effects of psychomotor stimulant drugs: clinical and neuropsychological implications. In: Creese I (ed) Stimulants: neurochemical, behavioral, and clinical perspectives. Raven Press, New York, pp 301-338

Schrot J, Thomas JR (1983) Alteration of response patterning by $d$-amphetamine on repeated acquisition in rats. Pharmacol Biochem Behav 18: 529-534

Received June 11, 1986 